\title{
Lenguajes de la violencia y violencia del lenguaje en la obra de Juan Mayorga
}

\section{Claire Spooner}

\section{(2) OpenEdition}

1 Journals

Edición electrónica

URL: https://journals.openedition.org/cher/1703

DOI: $10.4000 /$ cher. 1703

ISSN: 2803-5992

Editor

Presses universitaires de Strasbourg

\section{Edición impresa}

Fecha de publicación: 1 diciembre 2017

Paginación: 121-134

ISBN: 978-2-86820-962-7

ISSN: 1968-035X

Referencia electrónica

Claire Spooner, "Lenguajes de la violencia y violencia del lenguaje en la obra de Juan Mayorga», reCHERches [En línea], 19 | 2017, Publicado el 01 diciembre 2021, consultado el 12 febrero 2022. URL: http://journals.openedition.org/cher/1703 ; DOl: https://doi.org/10.4000/cher.1703

\section{(c) (i) (8)}

Ce(tte) œuvre est mise à disposition selon les termes de la Licence Creative Commons Attribution Pas d'Utilisation Commerciale - Partage dans les Mêmes Conditions 4.0 International. 


\title{
Lenguajes de la violencia y violencia del lenguaje en la obra de Juan Mayorga
}

\author{
CLAIRE SPOONER ${ }^{1}$
}

Las palabras preparan muertes, las palabras matan. La tortuga de Darwin, Juan Mayorga

\begin{abstract}
$\mathrm{V}$ iolencia y lenguaje se manifiestan a través de actos. Un acto violento se vale de la fuerza para someter o dominar a un individuo; esta violencia puede ser tanto física -entonces se manifiesta de forma directa y visible-como verbal o simbólica -en este caso los efectos de esos actos de palabra violentos son mucho más complejos. La noción de violencia simbólica del lenguaje es acuñada por Pierre Bourdieu, quien la relaciona con los habitus ${ }^{2}$ sociales y lingüísticos así como con la dominación de género.

Desde las obras teatrales de Juan Mayorga y escuchando las voces de los filósofos que en ella dialogan, interrogaremos los puntos de concordancia y discordancia entre violencia y lenguaje. Como en una elipse, que se dibuja con respecto a dos puntos que no tienen aparentemente ninguna relación entre sí (los focos), en el escenario de Juan Mayorga se reúnen los conceptos contradictorios de cultura y barbarie. Se cuestiona entonces el principio según el cual logos y violencia serían naturalmente excluyentes.
\end{abstract}

1 Doctora en Filología Hispánica por la Universidad de Toulouse Jean-Jaurès y en Filosofía por la Universidad Autónoma de Barcelona, alumna de la École normale supérieure Lettres et Sciences humaines de Lyon, Claire Spooner es profesora de lengua y literatura española.

2 «El habitus es esa especie de sentido práctico de lo que hay que hacer en una situación determinada -lo que, en deporte, se llama el sentido del juego, el arte de anticipar el desarrollo futuro del juego...» (Bourdieu 1997: 40). El habitus es una «suerte de trascendente histórico» (Bourdieu y Wacquant 1995: 83) que funciona como esquema abierto de producción, percepción y apreciación de prácticas y que se adquiere sólo mediante la práctica. 
La huella del filósofo alemán Walter Benjamin hace del escenario de Juan Mayorga una zona gris ${ }^{3}$ donde la razón convive con la violencia. Entran en escena y en conflicto ideas, cuerpos y palabras. Conviven la materia y la abstracción, la luz y la oscuridad; se solapan varios lenguajes, a veces contradictorios entre sí. Según el crítico teatral Bernard Dort:

la représentation théâtrale ne serait pas le lieu d'une unité retrouvée, mais celui d'une tension [...] entre l'universel et le particulier, l'éternel et le passager, entre l'abstrait et le concret, entre le texte et la scène. Elle ne réalise pas plus ou moins un texte : elle le critique, elle le force, elle l'interroge. Elle se confronte à lui et le confronte à elle. Elle est non un accord mais un combat. (1980)

El teatro como «arte del conflicto» resulta ser un lugar idóneo donde interrogarse tanto sobre los lenguajes de la violencia como sobre la violencia del lenguaje. En este artículo pondremos en tela de juicio las zonas grises que se dibujan en los textos de Juan Mayorga, a partir de las sabias palabras de una tortuga bicentenaria, pequeño testigo de los últimos doscientos años de Historia en La Tortuga de Darwin: "Las palabras preparan muertes, las palabras matan» (Mayorga 2008: 39).

\section{«Las palabras preparan muertes». Los lenguajes de la violencia en el escenario filosófico e histórico de Juan Mayorga}

La tarea del arte es, según Juan Mayorga (Fernández 1999), mostrar la violencia pasada, presente o futura; escribir y reflexionar sobre ella, sobre dónde y por qué se da. En el artículo "Violencia y olvido»", el dramaturgo afirma que «nunca tan urgentemente como hoy, la Filosofía debería tener entre sus primeras tareas el examen de los discursos de la violencia». En esta parte, examinaremos la naturaleza de los lenguajes de la violencia en la obra de Juan Mayorga.

«Las palabras preparan muertes», dice la tortuga Harriet: dicho de otro modo, el lenguaje prepara la manifestación extrema de la violencia contra el cuerpo. La muerte, la existencia de la no-existencia, precede al logos y le resiste. ¿En qué medida y cómo pueden las palabras preparar muertes? ¿Las planean, las urden, las disponen, las obvian, las aplazan, o las banalizan? ¿Las rechazan o las legitiman?

\section{Violencia del Estado y «Estado de excepción»: ecos benjaminianos en la obra de Juan Mayorga}

En La Tortuga de Darwin, Harriet afirma que los campos de concentración funcionan "como una máquina». La tortuga habla desde su punto de vista,

3 Con este concepto, Primo Levi se refiere al inaprensible espacio-tiempo de los campos de concentración, donde la excepción se vuelve norma, donde la violencia aniquiladora se convierte en ley hasta contaminar el lenguaje, destrozar e invalidar las categorías éticas.

4 Texto inédito, cedido por el autor. 
«desde abajo», aunque «subida a un montón de gafas, porque a la gente le quitan las gafas» (Mayorga 2014: 499) y, desde ahí, desde las ruinas, describe la puesta en escena del horror, de los «rituales»y las normas que rigen el campo:

El tren frena, las compuertas se abren y a la gente la separan en fuertes y débiles. A los flacos, a los viejos, a los niños, los hacen subir por una rampa, los desnudan, les cortan el pelo y los meten en una especie de hangar. De allí los sacan en carretillas y los queman en un gran horno. Todo, desde el tren hasta la chimenea, todo funciona como una máquina. (2014: 499)

La inmensa mascarada escenificada por el Comandante en Himmelweg para engañar al Delegado de la Cruz Roja, enviado para comprobar las condiciones de vida en un campo de concentración, es una mise en abyme de la escenificación del horror reinante en los campos. El Comandante se convierte en el director de una peculiar obra de teatro; nosotros asistimos a su puesta en escena, vemos cómo cuida cada detalle de las distintas secuencias que vienen a dar cuerpo a las piezas de una compleja maquinaria. El Comandante-director, un «hombre de cultura» (2014: 301) alecciona a Gottfried sobre la complejidad de la «obra de arte»: «Lo que Aristóteles viene a decir es que una obra de arte es tanto más bella cuanto más compleja, siempre y cuando esa complejidad esté bajo control» (2014: 319). Pero en la obra representada por los prisioneros del campo, está todo tan «bajo control» que el visitante inevitablemente sospecha algo. «Me pregunto si no será también él, el comandante, una pieza del mecano. Demasiado amable, demasiado culto» (2014: 303). El mecano, juguete o reloj, imágenes omnipresentes en la obra, son la metáfora de un sistema de exterminación disimulado por «palabras amables», falsas y perversas.

Mediante una utilización extrema y violenta del eufemismo, el lenguaje es usado como instrumento que permite encubrir la violencia del Estado y de la ideología que éste ensalza. Obras como el Traductor de Blumemberg, El Jardín quemado, y sobre todo Himmelweg, plantean el lenguaje como el aliado por antonomasia de toda forma de violencia estatal. Desde el título Himmelweg. Camino del cielo, está presente el eufemismo utilizado por los nazis para aludir a la rampa de cemento que, en los campos de concentración, conducía a la llamada «enfermería» -a las cámaras de gas-.

En El traductor de Blumemberg, Mayorga lleva a la escena el viaje de dos personas, Blumemberg y Calderón, pero también el viaje de las palabras y de las ideologías, puesto que éste tiene que traducir «la obra» de Blumemberg. En esta obra se plantea el vínculo entre lenguaje e ideología mediante la traducción y la propagación de la ideología fascista, la mistificación de la violencia y de la guerra. El libro por traducir, llamado «La Biblia de la violencia» (2014: 126), supuestamente es el "primer libro de una nueva Humanidad» (2014: 128), encarna, según descubre Calderón, «Las manos de Hitler y la voz de Blumemberg» (2014: 128), es decir que encierra «la teoría en la que se sustentará el andamiaje espiritual del Tercer Reich» (2004: 68). 
El filósofo Giorgio Agamben define el campo de Auschwitz como un lugar donde «el estado de excepción coincide perfectamente con la regla» ${ }^{5}$ (2003: 52). La violencia de Estado se encubre a través de metáforas y eufemismos, y va de la mano con una ideología fundada en una fe cegadora en el progreso, legitimando un necesario «Estado de Excepción», que se convierte en regla.

Tanto en sus ensayos como en sus obras teatrales, Juan Mayorga pone en tela de juicio las nociones de derecho y de justicia. En El traductor de Blumemberg, lo hace a través del personaje de Blumemberg, cuya ideología bebe de la de Georges Sorel. En ella se legitima la violencia, relacionada con «el anhelo de una justicia que no cabe en el derecho, que sólo cabe en su excepción» (Mayorga 2003a: 238). En los últimos años de su vida, Walter Benjamin emprende una lucha obstinada contra la concepción del fascismo, considerado como paréntesis o estado de excepción en una historia lineal, cuyo curso tiende hacia el progreso ${ }^{6}$. Para el filósofo alemán, el fascismo es la expresión de la Historia como catástrofe -no como progreso-. Y desde las ruinas de la Historia es desde donde se puede pensar el futuro: Walter Benjamin propone una lectura a contrapelo de la Historia, opuesta tanto al historicismo como al positivismo marxista que no ven en la historia más que la mecánica inexorable del progreso, y reivindican la existencia de un «sentido de la Historia». El filósofo alemán, al que Juan Mayorga dedica su tesis doctoral y al que da voz en su dramaturgia, invierte el curso de la Historia desde una interrupción dialéctica que rompe con el discurso dominante de los vencedores, y mira hacia el pasado para pensar el momento actual, y futuro.

\section{«Las palabras preparan muertes»: teorías sobre la violencia en el escenario}

Según la tortuga Harriet, «las palabras preparan muertes», nos acostumbran a ellas, y las banalizan. El Jardín quemado lleva a la escena los estragos físicos y mentales que generó la guerra civil española entre los individuos. En el patio de un asilo psiquiátrico están enterrados los cuerpos de doce pacientes que fueron fusilados "por error», en lugar de doce republicanos, quienes se «salvaron» a cambio de ocupar el lugar de doce «enfermos». El monólogo final de uno de esos hombres revela una visión hegeliana de la historia: «[...] (Su índice señala al fondo de la fosa, como si eligiese a doce hombres.) No es mi mano la que os elige,

5 La traducción es nuestra: « [...] ce lieu où l'état d'exception coïncide parfaitement avec la règle, où la situation extrême devient le paradigme même du quotidien ».

6 Juan Mayorga muestra en su tesis doctoral que las ideologías que legitiman un «estado de excepción» en vistas a un orden futuro (como la de Sorel), y las que piden la suspensión del derecho, por ejemplo a través de la huelga general, es decir, «el gesto con el que el dictador defiende el orden o el entusiasmo de los desesperados por suspenderlo» (2003a: 238), se apoyan en una misma visión teleológica de la Historia. «El anhelo de detención de la ciudad puede ser tan intenso como el de un milagro que interrumpa el continuo» (2003a: 238); la diferencia estriba en que el primero se funda sobre la noción de orden y sobre la certidumbre que el mundo está bien hecho, mientras que el segundo se identifica con la interrupción del orden, y con una visión fragmentaria del mundo. 
es la historia la que os ha señalado. Es la historia quien decide qué debe vivir y qué debe morir. ¿Qué vale una docena de hombres frente a la humanidad?» (Mayorga 2014: 182-183). El tema de esta obra hace hincapié en la noción de sacrificio, revoca la noción de «muertes útiles», y pone en tela de juicio la visión hegeliana de la Historia.

Como hemos mencionado más arriba, en El Traductor de Blumemberg, se exploran teorías sobre la violencia, las de Georges Sorel, y la de Ernst Jünger (Sobre el dolor o La emboscadura). En su ensayo «Violencia y olvido», Juan Mayorga alude a las teorías de Sorel y Jünger, quienes «ven en la violencia un factor de regeneración». Tanto Sorel como Jünger asocian la violencia a lo más auténtico de la vida, y ven en ella un factor de creación de identidad y un generador de sentido. Esta concepción utilitaria y aristocrática de la violencia corre parejas con la constitución de una «contrasociedad virtuosa»: «No sólo no tachan la violencia de inmoral, sino que descubren en ella el núcleo de una moral superior, de una moral de señores, o un valor más allá de toda consideración moral», escribe Juan Mayorga en el ensayo. Según Georges Sorel, la «violencia proletaria» no es un medio para la construcción de una sociedad emancipada de la «decadente sociedad burguesa», sino un bien en sí7.

En esta teoría, el sacrificio no sólo es algo necesario, sino que además tiene que ser algo «grande», magnificado, sublime. Para Jünger como para Blumemberg, los «sacrificados cobran esplendor» como comenta Mayorga en «El anciano más bello del mundo» ${ }^{8}$ (1999a: 3). «En mil novecientos dieciocho volví del frente con una cruz de hierro y veinte cicatrices» (Mayorga 2014: 137), dice Blumemberg. Jünger, como Blumemberg, son unos nostálgicos de la acción, de las guerras, de una violencia regeneradora: el personaje mayorguiano confía en que sus palabras den un sentido al dolor, a la violencia. Según Blumemberg, el sentido se tiene que buscar en un pasado guerrero" ${ }^{9}$ el «libro» de Blumemberg, «capaz de gobernar millones de almas» (2014: 126) tiene que dar «sentido a la vida y a la muerte de pueblos enteros» (2014: 126). Este discurso obedece a una lógica utilitaria y sacrificial que legitima la violencia e invisibiliza a las víctimas.

7 Frente a esta concepción utilitaria y aristocrática de la violencia, Walter Benjamin prefiere trazar una distinción entre dos tipos de violencia: la violencia mítica y la violencia divina. Según explica Juan Mayorga en "Violencia y olvido»: «La diferencia entre una y otra radica, según Walter Benjamin, en que la violencia mítica, conservadora de Derecho, exige el derramamiento de sangre inocente, mientras que la violencia divina interrumpe el Derecho para salvar la vida inocente».

8 También apunta que Jünger, cuya obra fue elogiada por los alemanes, nunca aceptó responsabilidad alguna en el desastre alemán: se veía a sí mismo como un observador limitado a registrar la catástrofe, fue un «observador excepcional de las heridas de Europa» (1999a: 3).

9 En este personaje encontramos una suerte de Jünger: durante el viaje, observa las heridas de Europa a partir de las suyas propias, y nos percatamos de que, como Jünger, «se lanzó a aquella guerra como a un gran carnaval, como a una fiesta para el corazón aventurero» según escribe el propio Mayorga (1999a: 3). 
Así, «las palabras preparan muertes», como dice Harriet, pero también las hacen: «las palabras matan». ¿Cómo se revela en el escenario la violencia performativa del lenguaje?

\section{«Las palabras matan»: la violencia del lenguaje}

«Ahí empieza siempre todo, en las palabras» (2014: 497), dice Harriet: en el escenario histórico y actual, político y teatral, las palabras se vuelven acción. Las obras de Juan Mayorga escenifican instantes en los que la fuerza performativa del lenguaje se convierte en un instrumento de poder y de violencia. El dramaturgo hace hincapié en la carga violenta de las palabras, que pueden «herir» ${ }^{10}$, de forma más o menos directa, generando siempre una lógica de dominación/sumisión entre hablantes.

¿En qué momentos la violencia emerge en el ámbito del lenguaje? ¿Cómo actúan la fuerza, la presión social, simbólica, económica, en y entre las palabras? ¿Se puede hablar sin dominar o ser dominado? Según escribe Ricardo Piglia en Tres propuestas para el nuevo milenio (y cinco dificultades), en el diálogo no importa «tanto qué es lo que el otro quiere decir, sino qué es lo que el otro quiere hacer con lo que dice» (2005: 8 y 9).

El teatro es un espacio idóneo desde donde observar «el funcionamiento real del lenguaje» como en una «situación de laboratorio» (Ubersfeld 1996c: 102). Entre los actos de lenguaje de John L. Austin, el acto ilocutorio tiene que ver con la intención del enunciador, contenida en el enunciado. La crítica teatral Anne Ubersfeld deduce que ese acto "construye cierto contrato entre yo y otro" (1996c: 92). A la luz de algunas obras de Juan Mayorga, estudiaremos el modo en que el lenguaje modifica y determina la relación entre los hablantes ${ }^{11}$.

\section{Lenguaje y acción. Cuando decir es hacer... daño}

La filósofa norteamericana Judith Butler retoma la teoría de los actos de lenguaje de John L. Austin, e insiste en que el lenguaje es «el acto y sus consecuencias» (2004: 28). Según John L. Austin, «decir es hacer». Judith Butler matiza esta afirmación: si decimos que una palabra «hace» una cosa, no expresamos sólo que la palabra significa una cosa, sino que esa significación es también la realización de esa cosa: «el principio del acto performativo estriba en esa aparente coincidencia entre significar y actuar» (2004: 72). Según la investigadora norteamericana, la performatividad es un acto que se reitera (no

10 Recurrimos conscientemente a un término propio del campo léxico del cuerpo, y más adelante, comentaremos con Judith Butler el hecho de que no existe un vocabulario específico para las heridas lingüísticas.

11 En el ámbito teatral, ese contrato es doble, como la enunciación: las palabras actúan entre los personajes/interlocutores presentes en el escenario, y también fuera de él, ya que tienen un efecto sobre los espectadores/lectores. 
se trata de un acto aislado), y es una interpelación social (no es una invención propia del individuo).

Dependemos del lenguaje desde el acto de nominación. Éste se repite cada vez que nos llaman (es el poder de interpelación del lenguaje según Althusser), o se dirigen a nosotros. En inglés, literalmente, «to give someone a name» significa darle un nombre a alguien. En el sentido figurado, significa insultar a alguien. Butler sugiere así que darle un nombre a alguien es también ejercer una forma de violencia hacia él, que los actos de violencia verbal (insultos) son una repetición del acto de nominación primitivo que le ha dado y continúa dándole existencia al sujeto (2004: 25$)$.

No es baladí que en Himmelweg, el Comandante modifique de entrada el nombre de Gershom Gottfried, al que elige como su «ayudante a la dirección», $y$ al que atribuye el papel de alcalde en la mascarada del campo-ciudad. El Comandante lo «bautiza» con un nombre alemán: «Gerhard», alegando que «Gershom es el equivalente judío de Gerhard» (Mayorga 2014: 317). La imposición y la repetición de este nuevo nombre recalcan la intención del Comandante de modificar la apariencia y la identidad de los judíos, tanto durante la mascarada como fuera de ella, y al mismo tiempo traduce violentamente el sentido inglés de la expresión «to give someone a name».

De este modo, Butler señala el poder ambivalente y paradójico del lenguaje, condición de la constitución del individuo en sujeto, de su existencia social, e instrumento de violencia. La performatividad del lenguaje genera una violencia «sin golpes» (Mayorga 1999b: 41). Hay varios grados y niveles de violencia lingüística, desde la frase performativa "es un niño» o "es una niña», que marca y determina el género del recién nacido, hasta las palabras que sirven para designar al otro y asociarle a un grupo de personas, a una «categoría», generando su estigmatización. Por eso la Tortuga Harriet afirma: "Las palabras marcan a la gente que hay que eliminar: "judío", "burgués", "comunista”, "fascista", “terrorista”...» (Mayorga 2014: 497).

Sin embargo, Judith Butler retoma y desarrolla la noción de «violencia simbólica» del lenguaje introducida por el sociólogo Pierre Bourdieu: según ella, «afirmar que el lenguaje hiere [...] es mezclar el vocabulario del cuerpo con el del lenguaje» (Butler 2004: 24). El vínculo metafórico entre vulnerabilidad física y vulnerabilidad lingüística revela que no hay vocabulario descriptivo propio de la herida lingüística, lo que vuelve más difícil su identificación.

\section{Lenguaje del poder}

\section{Lenguaje, violencia y poder}

Desde el lenguaje -esto es, desde el poder (empezando por el de hablar y ser escuchado)-, se preparan y se justifican actos violentos pasados y futuros. El logos se pone al servicio de la violencia, como se ve en La Paz perpetua, que escenifica un debate sobre la necesidad de la violencia de Estado para erradicar el terrorismo, encarnado por tres perros filósofos que combaten por un puesto de trabajo. 
De hecho, según apunta José Luis Aranguren:

[...] una historia implacablemente realista muestra o parece mostrar que la violencia se halla en el origen mismo del poder del Estado, que es inseparable de él. ¿En qué se diferencian «violencia» y «poder»? En el comienzo, en la implantación de todo Régimen, el poder es pura y simplemente -visto desde la situación anterior- violencia. Una vez establecido, el régimen se autolegitima. Con ello la violencia desnuda, primaria, elemental deja de ejercerse [...] Pero la violencia no ha desaparecido del todo de modo que la autolegitimada violencia aparece, pura y simplemente, como enforcement de la Ley, como defensa del orden público. (Aranguren 1973: 145)

De modo que cuando es legitimada por el poder, la violencia queda plasmada en el lenguaje estatal y en el aparato jurídico del nuevo régimen. «El discurso jurídico es una palabra creadora, que hace existir lo que enuncia», según Pierre Bourdieu, quien lo compara con un enunciado performativo casi divino: aquél es «el soporte por excelencia del sueño de poder absoluto»12 (1991: 21).

En Cartas de Amor a Stalin, este sueño se plasma en el personaje y en el discurso de Stalin, que sueña con un poder y un control absoluto de todo lo que se escribe y se piensa en su país. La violencia de Stalin hacia el escritor Bulgákov se manifiesta no tanto en sus palabras como en su silencio, que es una verdadera condena. Como lo expresa el propio Juan Mayorga en una entrevista: "Yo no creo que el silencio sea abstracto, sino que es tan concreto como una caricia, como un golpe» ${ }^{13}$. Por eso, ante las no-respuestas de Stalin a sus repetidas cartas y llamadas telefónicas, frente a la censura de todas sus obras, Bulgákov confiesa: «...mi amada patria me aniquila como escritor y como hombre. Quizá tenga que renunciar a mi patria para sobrevivir como escritor y como hombre» (Mayorga 2014: 241).

\section{El lenguaje del poder en Cartas de amor a Stalin: una relación epistolar ambivalente}

En Cartas de Amor a Stalin, Bulgákov dedica todas sus palabras ya no a la literatura, sino a una relación epistolar que absorbe todo su tiempo: le escribe cartas a Stalin para reclamar «su libertad como escritor». Así, se establece entre ambos una relación de dependencia recíproca, que gira en torno a palabras recitadas, repetidas, reescritas, recordadas, o silenciadas. Bulgákov se encierra en un mundo de palabras, un mundo ilusorio, hasta tal punto que «el lenguaje es precisamente aquello que le va disociando de la verdad» (Fernández 1999: 59), y de sí mismo. En cuanto a Stalin, logra imponer su ideología mediante una manipulación sádica y disimulada: por un lado, éste parece ofrecerle a Bulgákov

12 Nuestra traducción: «Le discours juridique est une parole créatrice, qui fait exister ce qu'elle énonce $[. .$.$] elle est sans doute le support par excellence du rêve de pouvoir$ absolu».

13 En una de nuestras entrevistas con el dramaturgo (del año 2008) editada en el anexo $\left(\mathrm{n}^{\circ} 1\right)$ de nuestra tesis doctoral: Spooner C., 2013, El teatro de Juan Mayorga: de la escena al mundo a través del prisma del lenguaje, Université de Toulouse Jean-Jaurès, $475 \mathrm{p}$. 
reingreso en el redil, puestos de trabajos, y salas para representar sus obras, pero con la condición de que capitule ante su amo, de que escriba «una obra que haga feliz a Stalin» (Mayorga 2014: 253).

Juan Mayorga se interesó por la peripecia de Mijaíl Bulgákov precisamente porque le permitía explorar el tema de la relación entre poder y libertad individual. A partir de la lectura de la correspondencia de Bulgákov y de Zamiatin con Stalin (Bulgákov/Zamiatin 1991), el dramaturgo concibió Cartas de amor a Stalin. Así lo escribe en el ensayo titulado «El poder como lo sueña el impotente»:

Se trataba de poner en escena una violencia que no necesita campos de concentración ni pelotones de fusilamiento; una violencia sin golpes, pero de la que sólo se puede escapar en una fuga imaginaria; una violencia incruenta, pero que conduce a la autocensura, al autoengaño, a la autodestrucción. (1999b: 41)

La ambigüedad del personaje de Stalin y también su fuerza se deben a que en la obra, éste es proyectado y convocado sobre el escenario por la mente del propio Bulgákov: «Se trataba de poner en escena a un creador y su demonio. O, simplemente, a un hombre y su demonio» (1999b: 41). Por eso la mujer de Bulgákov, ella, no ve nunca a Stalin, aunque sí percibe la enajenación de su marido: «Es como si esta casa estuviese endemoniada. Como si el demonio estuviese suelto por la casa» (Mayorga 2014: 244). Bulgákova queda progresivamente apartada de la relación Bulgákov-Stalin, hasta que decide marcharse (de casa y del país), llevando consigo el último manuscrito de su marido. La decisión final de Bulgákova tal vez esté presente en el silencio de la última acotación, «Bulgákov calla» (2014: 256), en el que oímos la resignación del escritor, pero también la posibilidad de su respuesta.

La «no resignación» de la figura femenina es un contrapunto importante en las obras de Juan Mayorga: pensamos en Rebecca y la chica del banco en Himmelweg, en la Mujer Alta de Animales Nocturnos, en la mujer de Scarpa -que sabe cantar, y se salva- en El Crítico. Son mujeres que deciden visibilizar la violencia («te estás convirtiendo en su esclavo», le dice la Mujer Alta a su marido), y con esta «no resignación» encarnan el gesto puro de la no violencia.

\section{Poder (social, económico, simbólico) del lenguaje}

Según matiza el sociólogo Pierre Bourdieu, el lenguaje es acción, sí, pero solo en la medida en que el hablante tiene un poder legítimo, el que no lo tiene ya puede repetir un mismo enunciado, éste no producirá jamás ningún efecto. El primero es legítimo, el segundo es un impostor. En Ce que parler veut dire, Bourdieu matiza y critica la tendencia formalista de John L. Austin:

Tratar de entender lingüísticamente el poder de las manifestaciones lingüísticas, buscar en el lenguaje el principio de la lógica y de la eficacia del lenguaje de institución, eso es olvidarse que la autoridad adviene fuera del lenguaje [...]. Esta autoridad, el lenguaje a lo sumo la representa, la manifiesta, la simboliza ${ }^{14}$. (1991: 105)

14 Nuestra traducción. 
¿Cómo percibir esta autoridad que «adviene fuera del lenguaje» y se revela en él? Con la noción de habitus ${ }^{15}$, Bourdieu plantea una teoría del conocimiento vinculada con el cuerpo, sobre la incorporación de las normas. Sin embargo, según Judith Butler, Bourdieu no logra entender cómo la parte corporal del discurso se resiste y fracasa frente a las normas que lo intentan regular. ¿Cómo distinguir de manera segura al impostor del que tiene autoridad legítima? ¿Cuál es la «fuerza» de lo performativo? Eso es lo que se pregunta Judith Butler. Para la norteamericana, el habitus -la vida social del cuerpo- está estructurado por una forma de performatividad, menos explícita que la que opera en los ejemplos relacionados con el poder estatal, el matrimonio, etc. Según Butler, la interpelación lingüística evocada anteriormente tiene un efecto, es decir que determina la vida social del cuerpo (el habitus). Así, el acto performativo social desempeña un papel esencial en la formación del sujeto.

En Animales Nocturnos, Juan Mayorga escenifica este estrecho y tácito vínculo entre el lenguaje y la condición social del locutor. El personaje del Hombre Bajo se aprovecha de la situación del Hombre Alto, un inmigrante «sin papeles», para convertirlo progresivamente en su esclavo. Queda plasmada la "performatividad tácita del poder» de la que habla Butler, que establece las relaciones de dominación / sumisión.

Según Ricardo Piglia, «el consenso no surge del diálogo sino de la lucha y de las relaciones de fuerzas que se juegan de modo distinto en situaciones distintas» (2005: 9). La comunicación entre el Hombre Alto y el Hombre Bajo en Animales Nocturnos se establece bajo una relación de dominación ambigua, que de alguna manera se acaba invirtiendo: «No me gusta beber solo. No vuelva a levantarse sin mi permiso, por favor, no me obligue a hacer lo que no quiero hacer. Estoy intentando ser amable. [...] Yo no redacté esa ley, pero ella ha cambiado nuestra relación» (Mayorga 2014: 338). La soledad y la perversión de un hombre lo conducen a apropiarse de la vida de su vecino, aprovechándose de su situación de «extranjero»: «Entonces tenemos un secreto. Tú y yo. Compartimos un secreto», le dice el Hombre Bajo al Alto (2014: 348). El conocimiento de ese secreto hace que él será quien puede preguntar, dirigir las conversaciones, entrometerse en el espacio privado del otro. La mujer del Hombre Alto ve de lejos la primera de esas conversaciones, y dice que no los interrumpió porque «me pareció que estabais pasando un buen rato» (2014: 338). Pero donde puede haber una ilusión de diálogo libre, el «sin papeles» sabe perfectamente que tiene que contestar preguntas que él nunca podría formular, ni tampoco puede rechazar el diálogo.

De manera similar, en Hamelin, a partir de la escenificación de un caso de abuso hacia un menor, se elabora toda una reflexión sobre el lenguaje como lugar de ejercicio del poder. «Ésta es una obra sobre el lenguaje. Sobre cómo se forma

15 Ver la nota 1 para la definición de Pierre Bourdieu. Mencionaremos aquí la de Althusser, citada por Judith Butler: «El habitus, son aquellos rituales cotidianos incorporados a través de los cuales una cultura produce y alimenta la creencia en su propia "evidencia"» (Butler 2004: 203). Nuestra traducción. 
y cómo enferma el lenguaje» (2014: 412) dice el Acotador. Hamelin escenifica la tesis de Judith Butler según la que, en función de las relaciones de poder que lo determinan y lo legitiman, el lenguaje «se forma y enferma». La psicopedagoga Raquel, y el juez Montero, emplean una jerga que denota poder; su lenguaje tiene una fuerza performativa social -su voz de profesionales será escuchada como legítima para juzgar el caso del niño y tomar «la mejor decisión»-. El juez y la psicopedagoga, que acusan a la familia de Josemari de haberle dejado estar en contacto con el presunto pederasta Rivas, arman un discurso coherente, legítimo (el «lenguaje autorizado» de Bourdieu), mientras que los familiares del niño, más humildes, no encuentran las palabras para defenderse. Dicho de otro modo, "además de instrumento de comunicación, la lengua es también signo exterior de riqueza e instrumento de poder» (Bourdieu 1991: contraportada). La precariedad social de los padres de Josemari es en primer lugar una pobreza lingüística, "porque son incapaces de configurar un relato que ordene sus experiencias», según dice Juan Mayorga en una entrevista (Spooner 2013: 473).

Ricardo Piglia destaca en el texto citado anteriormente que «el Estado tiene una política con el lenguaje, busca neutralizarlo, despolitizarlo y borrar los signos de cualquier discurso crítico» (2005: 38). Este fenómeno lo pone de realce el personaje del Acotador en Hamelin, al comentar el lenguaje empleado por Raquel: “Proyecto". Está hablando de un niño de diez años. "Proyecto". La palabra debería retumbar en el escenario» (Mayorga 2014: 412). «Proyecto», "paciente», «unidad familiar», son palabras que evidencian que el lenguaje de Raquel «es aparentemente neutral, pero sirve sus intereses» (Spooner 2013: 460) y reduce la posibilidad de la respuesta, del diálogo, de la crítica.

Al fin y al cabo, Juan Mayorga nos muestra que la violencia acecha permanentemente, ya sea en la relación de un hombre con el Estado (Cartas de amor a Stalin), con un amigo (Animales Nocturnos), con su familia, o entre el mundo de los niños y el de los adultos, supuestamente «protectores» (Hamelin). «Se puede matar moralmente todos los días de su vida a un hombre simplemente ejerciendo una latente violencia», afirma Juan Mayorga en una entrevista (Fernández 1999: 59). Como lo hemos tratado de mostrar a la luz de los escritos de Judith Butler, la obra de Juan Mayorga hace hincapié en que la vida social está contaminada de momentos en los que hay alguien que está intentando imponerse sobre el otro y aniquilarlo. En el ensayo «El teatro es un arte político», el dramaturgo pone de realce la lógica binaria que rige las relaciones sociales y políticas: "[n]os están educando para dominar o para ser dominados; para dominar a otros o para resignarnos al dominio de otros. Nos están educando para matar o para morir» (2003b: 10). Esta educación se propaga en los habitus sociales, y lingüísticos: «Lo que uno puede decir, lo que uno incluso se atreve a pensar con palabras, lo que uno se atreve a preguntar está coartado por relaciones de poder de cualquier signo, no hay una verdadera comunicación libre, un verdadero intercambio libre» afirma el autor (Spooner 2013: 477). 


\section{La violencia aboca al abismo}

La puesta en escena de lenguajes de la violencia y la dramatización de la violencia del lenguaje en la obra de Juan Mayorga nos llevan a pensar en la noción de límite -el límite de la existencia (muerte), la aporía del lenguaje y de lo visible (silencio)-. Según Juan Mayorga, «en el campo, la filosofía enmudece, si es que no es capaz de aprender a hablar otra vez» ${ }^{16}$. El filósofo que se arriesga a pisar Auschwitz experimenta la «fragilidad de su oficio»: los límites de la razón pura, los límites de lo pensable, de lo decible.

La escritura y la representación teatral de los campos de concentración (Himmelweg), de la guerra (El jardín quemado, El traductor de Blumemberg), del terrorismo ( $L a$ paz perpetua), de distintos tipos de violencia -jurídica, estatal, moral y social- (Animales Nocturnos, Cartas de amor a Stalin, Últimas palabras de Copito de Nieve, Hamelin) constituyen un gesto filosófico: el de la confrontación con los límites. Al espectador/lector del teatro mayorguiano se le invita a experimentar humildemente algo parecido a lo que Gilles Deleuze llama la "desterritorialización ${ }^{17}$ : viajar hacia sus propios límites, los de la humanidad y de la razón.

Dicho de otro modo, la violencia aboca al abismo, al límite, al silencio. Tal vez nos pueda ser útil mencionar la distinción terminológica entre violencia y brutalidad que propone Marie-Thérèse Mathet en Brutalité et représentation: la violencia pertenece al ámbito de lo simbólico, del lenguaje, de la representación, mientras la brutalidad se refiere a lo Real en el sentido lacaniano, es decir lo incomprensible (2006: 8), aquello que se manifiesta en la aporía del lenguaje (Barthes 1957: 105). Así, el término «violencia» remite a lo que hemos llamado los «lenguajes de la violencia», es decir, aquellas palabras que preparan muertes, las teorías sobre la violencia que la legitiman y le dan un valor simbólico, un sentido. Según René Girard, la violencia siempre forma parte de un sacrificio y constituye una escenografía, en la que cobra un sentido. Al contrario, la brutalidad es invisible e indecible: es un hueco, es ese vacío en torno al que se construye el arte. Estaba ahí antes del lenguaje, y permanece después, como residuo que se resiste a la significación, fuera del lenguaje. Es lo que desde el cuerpo resiste a las normas sociales, lingüísticas, a lo que aludía Judith Butler.

La brutalidad está siempre presente de forma latente en la obra de Mayorga como aquello que escapa al lenguaje y al control, como algo incomprensible que tiene que ver con el cuerpo, con la muerte y con la capacidad performativa del lenguaje de hacer que la muerte sea. La brutalidad es también una pregunta, un conflicto irresoluble que nos mantiene en estado de alerta permanente. Por eso la dramaturgia de Juan Mayorga, fiel a la visión benjaminiana de la Historia,

16 Texto inédito del dramaturgo de presentación de la obra de Reyes Mate: Por los campos de exterminio y Memoria de Auschwitz.

17 Es un concepto creado por Gilles Deleuze y Félix Guattari en L'Anti-CEdipe: «Se déterritorialiser, c'est quitter une habitude, une sédentarité. Plus clairement, c'est échapper à une aliénation, à des processus de subjectivation précis» (Deleuze y Guattari 1972: 162). 
escenifica los momentos de conflicto y de crisis. Como lo expone la investigadora Gabriela Cordone, para Walter Benjamin, la discontinuidad permite pensar el pasado en sus vínculos con el presente: «en el instante de un relámpago, todo el pasado acude al presente y lo ilumina» (Cordone 2011: 112). Precisamente desde ahí, desde la violencia de unos paisajes en ruinas, es desde donde se puede pensar el futuro. A propósito del filósofo alemán, Juan Mayorga escribe:

La suya no es tampoco una imagen pesimista de la historia. En la narración del pasado encuentra una -pequeña- posibilidad para la emancipación: el recuerdo del pasado fallido es fuente de esperanza para la actualidad. [...] Las fuentes de sentido son descubiertas por Benjamin en las fallas del pasado. [...] El carácter fragmentario del texto es coherente con esa paradójica contemplación de las ruinas. (2003a: 78 )

En la Tortuga de Darwin, Harriet recuerda al «Ángel de la Historia» de Walter Benjamin, que contempla las ruinas de la Historia, y no puede apartar la vista de las catástrofes de las que ha sido testigo:

De pronto, todo vuelve: el brillo del Danubio un veintiocho de marzo, los ojos de un guapo muchacho en Ponte Vecchio... Y también cosas malas, cosas que hace daño recordar. Ahora sé que para vivir hay que olvidar, y cuando se ha vivido mucho hay que olvidar mucho. De golpe, siento el peso de tantos muertos. Todos esos muertos, yo los llevo dentro. (Silencio.) (Mayorga 2014: 499)

La tortuga benjaminiana se siente en deuda con los muertos de la Historia, nos invita a recordarlos, a escuchar su silencio. Nos guía, tenaz, urgente y humildemente ante el precipicio de la brutalidad y el límite. El universo dramático de Juan Mayorga plasma (sin llegar a fijarla nunca) la zona gris de Primo Levi, convirtiéndola en un lugar de resistencia a cualquier lógica binaria, a las oposiciones vencedor/vencido, o pasado/futuro, y a la violenta política de neutralización del lenguaje y de las conciencias. Con la brutal interrogación del espectador/lector se abren escenarios absolutamente otros, que dibujan una «tercera vía», «lugar[es] para la crítica y para la utopía» (Mayorga 2012: 86).

\section{Bibliografía}

Agamben G., 2003, Ce qui reste d'Auschwitz, Paris, Payot.

Aranguren J.L., 1973, «Sobre la evitabilidad o inevitabilidad de la violencia», in: El futuro de la Universidad y otras polémicas, Madrid, Taurus ediciones.

Barthes R., 1957, «Photos-chocs», in: Mythologies, Paris, Seuil.

Bourdieu P., 1991, Ce que parler veut dire. L'économie des échanges linguistiques, Poitiers, Fayard.

Bourdieu P. y Wacquant L., 1995, Respuestas. Por una Antropología Reflexiva, México, Grijalbo.

Bourdieu P., 1997, «El nuevo capital», in: Razones Prácticas. Sobre la teoría de la acción, Barcelona, Anagrama. 
Bulgákov M. y Zamiatin E., 1991, Cartas a Stalin, Víctor Gallego (trad.), Madrid, Grijalbo.

Butler J., 2004, Le pouvoir des mots. Discours de haine et politique du performatif, Paris, Éditions Amsterdam.

Cordone G., 2011, «La Tortuga de Darwin, de Juan Mayorga: Hacia una lectura benjaminiana de la Historia», Estreno. Cuadernos del teatro español contemporáneo, 37.2, p. 101-114.

Deleuze G. y Guattari F., 1972, L'Anti-CEdipe, Paris, Minuit.

Dort B., 1980, «Le Monde du dimanche» (12 octobre).

Fernández J.R., 1999, «Conversación con Juan Mayorga», Primer Acto, 280, p. 54-59.

Mathet M.-T., 2006, Brutalité et représentation, Paris, L'Harmattan.

Mayorga J., «Violencia y olvido», artículo inédito.

Mayorga J., texto inédito de presentación de Por los campos de exterminio y Memoria de Auschwitz, de Reyes Mate.

Mayorga J., 1999a, «El anciano más bello del mundo», El Cultural, 3.

Mayorga J., 1999b, «El poder como lo sueña el impotente», Las puertas del drama, 41.

Mayorga J. y Mate R., 2000, «Los avisadores del fuego», Isegoría, 23, p. 45-67.

Mayorga J., 2003a, Revolución conservadora y conservación revolucionaria. Política y memoria en Walter Benjamin, Rubí (Barcelona), Anthropos.

Mayorga J., 2003b, «El teatro es un arte político», Primer Acto, 297, p. 10.

Mayorga J., 2004, «Estatuas de ceniza», conferencia impartida en la Universidad de Málaga, publicada en edición bilingüe en Altra cenere, Florencia, Aliena Editrice.

Mayorga J., 2012, «Teatro y cartografía», Boletín Hispánico Helvético, 19, p. 86-87.

Mayorga J., 2014, Teatro 1989-2014, Segovia, la uÑa RoTa.

Spooner C., 2013, El teatro de Juan Mayorga: de la escena al mundo a través del prisma del lenguaje, Université de Toulouse Jean-Jaurès [inédita].

Ubersfeld A., 1996a, Lire le théâtre I, Paris, Belin.

Ubersfeld A., 1996b, Lire le théâtre II. L'école du spectateur, Paris, Belin.

Ubersfeld A., 1996c, Lire le théâtre III. Le dialogue de théâtre, Paris, Belin. 